\title{
Diagnostic indicators for peptic ulcer perforation at a tertiary care hospital in Thailand
}

This article was published in the following Dove Press journal:

Clinical and Experimental Gastroenterology

8 December 201I

Number of times this article has been viewed

\section{Chutikarn Suriya' \\ Nongyao Kasatpibal ${ }^{2}$ \\ Wipada Kunaviktikul ${ }^{2}$ \\ Toranee Kayee ${ }^{3}$ \\ 'Clinical Epidemiology, Faculty of Medicine, Chiang Mai University, \\ ${ }^{2}$ Faculty of Nursing, Chiang Mai University, ${ }^{3}$ Department of Surgery, Nakornping Hospital, Chiang Mai, Thailand}

Introduction: Limited data currently exists regarding the diagnostic indicators of peptic ulcer perforation for early detection among patients in Thailand. Delayed diagnosis and treatment for an ulcer can be life-threatening, resulting in shock or death.

Objective: To determine the diagnostic indicators of peptic ulcer perforation.

Material and methods: A cohort study was conducted in a tertiary care hospital in Thailand from 2005 to 2009. Peptic ulcer patients aged 15 years and over admitted to the surgical department were included. The diagnostic indicators used criteria of the patients' final diagnoses and operations, coded according to the International Statistical Classification of Diseases and Related Health Problems, 10th Revision, which included patient profiles, gender, age, coexisting illnesses, personal habits, signs and symptoms, laboratory investigations, radiological finding, and treatment role. Exponential risk regression analyses to obtain relative risk (RR) estimates for diagnostic indicators were analyzed using Stata ${ }^{\circledR}$ statistical software package, version 11 (StataCorp LP, College Station, TX).

Results: The study included 1290 patients. Of these, 57\% reported perforated peptic ulcer. Multivariate analysis showed five diagnostic indicators: signs and symptoms including intense abdominal pain $(\mathrm{RR}=1.53,95 \%$ confidence interval $[\mathrm{CI}] 1.14-2.06)$, tenderness $(\mathrm{RR}=1.94$, $95 \%$ CI 1.17-3.21), and guarding $(R R=1.52,95 \%$ CI 1.05-2.20); $\mathrm{X}$-ray with free air $(\mathrm{RR}=2.80$, 95\% CI 2.08-3.77); and referral from other hospitals ( $R R=1.37,95 \%$ CI 1.03-1.82).

Conclusion: Five diagnostic indicators for peptic ulcer perforation monitoring were suggested from this study. Improving diagnostic indicators for medical care may improve the outcome of patients that have perforated peptic ulcer.

Keywords: diagnostic indicator, peptic ulcer perforation, Thailand

\section{Introduction}

Peptic ulcer perforation (PUP) is the most common severe complication for a peptic ulcer. ${ }^{1-3}$ Many studies have assessed the risk factors associated with PUP. ${ }^{4-8}$ The incidence of PUP in Thailand was $10 \%$ of peptic ulcers. ${ }^{9}$ PUP accounts for $5 \%$ of all abdominal emergencies. ${ }^{1-3,10}$ PUP is a major cause of death worldwide and continues to be a serious health problem in many hospitals in Thailand. In Nakornping Hospital (Chiang Mai), the PUP rate increased from 14.1\% in 1994 to $21.9 \%$ of all peptic ulcer patients in the surgical department in $2004 .{ }^{11}$ It is one of the top five conditions for hospital admissions. ${ }^{1-3,10,11}$

In clinical practice, patients with PUP usually present with a sudden onset of severe abdominal pain and gastrointestinal bleeding. ${ }^{2,10}$ Patients with PUP range from individuals who are completely asymptomatic to those who develop severe complications.
Correspondence: Chutikarn Suriya

Clinical Epidemiology, Faculty of Medicine, Chiang Mai University, Chiang Mai, Thailand 52000

Tel +6653 I2I I22-4 ext II

Fax +6653 I2I 125

Email suriya.xunxin@gmail.com which permits unrestricted noncommercial use, provided the original work is properly cited. 
Comprehensive understanding of the signs, symptoms, and pathogenesis of PUP requires an experienced medical management team with knowledge of indicators associated with PUP.

Currently, there is no gold standard for diagnosis of PUP and there is limited data regarding diagnostic indicators for early detection of PUP among patients in Thailand. The aim of this study was to determine specific diagnostic indicators of PUP based on patients' personal habits, physical examination, signs and symptoms, laboratory investigations, radiological finding, and treatment role, which would be useful for doctors and nurses in emergency or surgical departments. These indicators would establish prompt diagnosis in order to reduce PUP and risk of death from delayed treatment. ${ }^{5,7,12}$ Diagnostic indicators of PUP are needed for early detection among patients undergoing perforation in order to improve clinical outcome.

\section{Material and methods}

\section{Inclusion criteria and diagnosis}

Patients aged 15 years or older who were admitted to the surgical department of Nakornping Hospital for severe abdominal pain, gastrointestinal bleeding, or hemorrhage due to gastric or duodenal ulcer perforation, and with signs and symptoms of serious bleeding or intense abdominal pain, were included in the study. Invariably, the definitive diagnosis for PUP was obtained postoperation for the patients' final diagnosis of gastric or duodenal ulcer.

\section{Exclusion criteria}

Patients with misplaced or incomplete records and patients diagnosed with perforation from malignant ulcers were excluded.

The medical records of all patients undergoing surgery for PUP from January 1, 2006 to December 31, 2009 at a tertiary care hospital in Thailand were reviewed retrospectively. The project was approved by the Ethical Review Committee for Research in Human Subjects, Chiang Mai University's Faculty of Medicine and Ethics Committee, and the Ethical Committee and/or the director of Nakornping Hospital.

Subsequently, data collection including emergency records, nurse notes, diagnostic reports, routine laboratory and radiological findings, progress notes, and operative notes were reviewed by the research nurse and attending physicians. These were obtained from patients' medical records, nurse notes, and anesthetic records. Data included patient demographics (gender and age), coexisting illnesses (diabetes mellitus, hypertension, chronic obstructive pulmonary disease, asthma, liver cirrhosis, heart disease, renal disease, and arthritis), personal habits (smoking, alcohol consumption, nonsteroidal antiinflammatory drug usage, and history of peptic ulcer), signs and symptoms (hematemesis, intense abdominal pain, tenderness, guarding, melena, systolic blood pressure, and pain onset time), laboratory investigations (hemoglobin, hematocrit, blood urea nitrogen, and creatinin), radiological finding (X-ray with free air), and treatment role (referral from other hospitals). This study period found that no patients had recurring perforations or multiple admissions.

Following review, pertinent data were recorded on preprinted data collection forms. Completed data collection forms were edited and analyzed at the study data processing center.

\section{Definitions}

PUPs included gastric ulcer perforation and duodenal ulcer perforation. Final diagnosis was determined postoperation according to the International Statistical Classification of Diseases and Related Health Problems, 10th Revision: gastric ulcer (coded K25, subcategories 25.1, 25.2, 25.5, 25.6) or duodenal ulcer (coded K26, subcategories 26.1, $26.2,26.5,26.6) .^{13}$

\section{Statistical analysis}

Demographic data were presented as percentage, mean, and standard deviation. All continuous data were tested for normal distribution with the Shapiro-Wilk test. Parametric tests were used based on normal distributions, and nonparametric tests were performed when assumptions were not met.

Contingency tables were constructed to analyze the relationships between PUP patients and peptic ulcer with no perforation patients. Comparison of data between the two patient groups were undertaken with Pearson's chi-square test or Fisher's exact test for categorical data and Student's t-test or Wilcoxon rank-sum test for continuous data. All variables, explored by univariable analyses, were entered into a multivariable exponential risk regression analysis to evaluate the relative risk (RR) of PUP for the diagnostic variables. Differences were considered statistically significant when $P<0.05$. All analyses were performed using Stata $^{\circledR}$ statistical software package, version 11 (StataCorp LP, College Station, TX).

\section{Results \\ Patient characteristics}

During the study period, 1290 patients were included in the study; 285 patients with misplaced or incomplete records were excluded. Of included patients, 57\% (740 patients) 
Table I Baseline characteristics of peptic ulcer perforation

\begin{tabular}{|c|c|c|c|c|c|}
\hline \multirow[t]{2}{*}{ Characteristics } & \multicolumn{2}{|l|}{ PUP } & \multicolumn{2}{|l|}{ PUNP } & \multirow[t]{2}{*}{$P$ value } \\
\hline & $(n=740)$ & $\%$ & $(n=550)$ & $\%$ & \\
\hline \multicolumn{6}{|l|}{ Gender } \\
\hline Male & 436 & 58.92 & 453 & 82.36 & $<0.001$ \\
\hline Female & 304 & 41.08 & 97 & 17.64 & \\
\hline \multicolumn{6}{|l|}{ Age (years) } \\
\hline$<60$ & 225 & 30.41 & 420 & 76.36 & $<0.001$ \\
\hline$\geq 60$ & 515 & 69.59 & 130 & 23.64 & \\
\hline Median (IQR) & 71 (14-92) & & $52(32-85)$ & & $<0.001$ \\
\hline \multicolumn{6}{|l|}{ Coexisting illnesses } \\
\hline Diabetes mellitus & 141 & 19.05 & 58 & 10.55 & $<0.001$ \\
\hline Hypertension & 132 & 17.84 & 188 & 34.08 & $<0.001$ \\
\hline COPD & 66 & 8.92 & 32 & 5.82 & 0.038 \\
\hline Asthma & 3 & 0.41 & 3 & 0.55 & 0.51 \\
\hline Liver cirrhosis & 75 & 10.14 & 3 & 0.55 & $<0.001$ \\
\hline Heart disease & 120 & 16.22 & 51 & 9.27 & $<0.001$ \\
\hline Renal disease & 67 & 90.5 & 62 & 11.27 & 0.189 \\
\hline Arthritis & 75 & 10.14 & 37 & 6.73 & 0.032 \\
\hline History of peptic ulcer & 398 & 53.78 & 93 & 16.91 & $<0.001$ \\
\hline \multicolumn{6}{|l|}{ Personal habits } \\
\hline Smoking & 513 & 69.32 & 252 & 45.82 & $<0.001$ \\
\hline Alcohol consumption & 399 & 53.92 & 211 & 38.36 & $<0.001$ \\
\hline NSAID usage & 199 & 26.89 & 100 & 18.18 & $<0.001$ \\
\hline \multicolumn{6}{|l|}{ Signs and symptoms } \\
\hline Hematemesis & 200 & 27.03 & 229 & 41.64 & $<0.001$ \\
\hline Intense abdominal pain & 683 & 92.30 & 214 & 38.91 & $<0.001$ \\
\hline Tenderness & 714 & 96.49 & 261 & 47.45 & $<0.001$ \\
\hline Guarding & 684 & 92.43 & 155 & 28.18 & $<0.001$ \\
\hline Melena & 57 & 7.70 & 129 & 23.45 & $<0.001$ \\
\hline \multicolumn{6}{|c|}{ Systolic blood pressure $(\mathrm{mmHg})$} \\
\hline$\geq 100$ & 303 & 40.95 & 502 & 91.27 & $<0.001$ \\
\hline$<100$ & 437 & 59.05 & 48 & 8.73 & \\
\hline Median (IQR) & $98(68-162)$ & & $119(99-215)$ & & $<0.001$ \\
\hline \multicolumn{6}{|l|}{ Pain onset time (hours) } \\
\hline$<24$ & 323 & 43.65 & 522 & 94.91 & $<0.001$ \\
\hline$\geq 24$ & 417 & 56.35 & 28 & 5.09 & \\
\hline Median (IQR) & $24(I-68)$ & & $6(1-47)$ & & $<0.001$ \\
\hline \multicolumn{6}{|l|}{ Laboratory finding } \\
\hline \multicolumn{6}{|l|}{ Hemoglobin (mg/dL) } \\
\hline Mean \pm SD & $10.55 \pm 2.26$ & & $10.41 \pm 2.52$ & & 0.853 \\
\hline \multicolumn{6}{|l|}{ Hematocrit (\%) } \\
\hline$\geq 30$ & 344 & 46.49 & 235 & 42.73 & 0.179 \\
\hline$<30$ & 396 & 53.51 & 315 & 57.27 & \\
\hline Mean \pm SD & $30.80 \pm 6.81$ & & $30.99 \pm 7.83$ & & 0.354 \\
\hline \multicolumn{6}{|l|}{ BUN (mg/dL) } \\
\hline Median (IQR) & $30.34(3.60-213.50)$ & & $26.50(1.00-111.80)$ & & $<0.001$ \\
\hline \multicolumn{6}{|l|}{ Creatinin (mg/dL) } \\
\hline Median (IQR) & $2.48(0.25-31.5)$ & & $\mathrm{I} .69(0.25-6 \mathrm{I})$ & & $<0.001$ \\
\hline \multicolumn{6}{|l|}{ BUN/creatinin ratio } \\
\hline$<12$ & 142 & 19.19 & 225 & 40.91 & $<0.001$ \\
\hline$\geq 12$ & 598 & 80.81 & 325 & 59.09 & \\
\hline \multicolumn{6}{|l|}{ Radiological finding } \\
\hline \multicolumn{6}{|l|}{ X-ray with free air } \\
\hline No & 70 & 9.46 & 494 & 89.82 & $<0.001$ \\
\hline Yes & 670 & 90.54 & 56 & 10.18 & \\
\hline
\end{tabular}


Table I (Continued)

\begin{tabular}{|c|c|c|c|c|c|}
\hline \multirow[t]{2}{*}{ Characteristics } & \multicolumn{2}{|l|}{ PUP } & \multicolumn{2}{|l|}{ PUNP } & \multirow[t]{2}{*}{$P$ value } \\
\hline & $(n=740)$ & $\%$ & $(n=550)$ & $\%$ & \\
\hline \multicolumn{6}{|l|}{ Treatment role } \\
\hline \multicolumn{6}{|c|}{ Referral from other hospitals } \\
\hline No & 57 & 7.70 & 230 & 41.82 & $<0.001$ \\
\hline Yes & 683 & 92.30 & 320 & 58.18 & \\
\hline
\end{tabular}

Abbreviations: BUN, blood urea nitrogen; COPD, chronic obstructive pulmonary disease; IQR, interquartile range; NSAID, nonsteroidal antiinflammatory drug; PUNP, peptic ulcer with no perforation; PUP, peptic ulcer perforation.

reported PUP, 58.92\% (436 patients) were male, and the median age was 71 (interquartile range 14-92) years, with $69.59 \%$ (515 patients) aged $\geq 60$ years. There were statistical differences between PUP patients and peptic ulcer with no perforation patients in coexisting illnesses (diabetes mellitus $P<0.001$, hypertension $P<0.001$, chronic obstructive pulmonary disease $P=0.038$, liver cirrhosis $P<0.001$, heart disease $P<0.001$, arthritis $P=0.032$, and history of peptic ulcer $P<0.001$ ), personal habits (smoking $P<0.001$, alcohol consumption $P<0.001$, and nonsteroidal antiinflammatory drug usage $P<0.001$ ), signs and symptoms (hematemesis $P<0.001$, intense abdominal pain $P<0.001$, tenderness $P<0.001$, guarding $P<0.001$, melena $P<0.001$, systolic blood pressure $<100 \mathrm{mmHg} P<0.001$, and pain onset time $\geq 24$ hours $P<0.001$ ), laboratory investigations (blood urea nitrogen/creatinin ratio $\geq$ twelvefold $P<0.001$ ), radiological finding (X-ray with free air $P<0.001$ ), and treatment role (referral from other hospitals $P<0.001$ ). In other variables, there were no statistical differences (Table 1).

\section{Diagnostic indicators}

The results of univariable analyses of diagnostic indicators, including patient demographics and clinical variables from Table 1, in relation to PUP are presented in Table 2. The following variables were significantly associated with PUP in the crude analyses: male patients $(\mathrm{RR}=1.55,95 \%$ confidence interval [CI] 1.42-1.69); age $\geq 60$ years $(\mathrm{RR}=2.29,95 \% \mathrm{CI}$ 1.96-2.68); coexisting illnesses (diabetes mellitus $[R R=1.29$, 95\% CI 1.07-1.55], liver cirrhosis $[\mathrm{RR}=1.75,95 \% \mathrm{CI}$ 1.38-2.23], heart disease [RR $=1.27,95 \%$ CI 1.04-1.54], and history of peptic ulcer [RR $=1.89,95 \%$ CI 1.64-2.19]); personal habits (smoking [RR $=1.55,95 \%$ CI $1.33-1.81]$, alcohol consumption $[R R=1.30,95 \%$ CI 1.13-1.51], and nonsteroidal antiinflammatory drug usage $[\mathrm{RR}=1.22,95 \%$ CI 1.04-1.40]), signs and symptoms (intense abdominal pain $[\mathrm{RR}=5.25,95 \% \mathrm{CI} 4.01-6.88]$, tenderness $[\mathrm{RR}=8.87,95 \%$ CI 6.00-13.12], guarding [RR $=6.57,95 \%$ CI 5.00-8.62], systolic blood pressure $<100 \mathrm{mmHg}[\mathrm{RR}=2.39,95 \% \mathrm{CI}$
1.01-2.77], and pain onset time $\geq 24$ hours $[R R=2.45$, 95\% CI 2.12-2.83]); laboratory investigations (blood urea nitrogen/creatinin ratio $\geq$ twelvefold $[R R=1.67,95 \%$ CI 1.39-2.01]); radiological finding (X-ray with free air $[\mathrm{RR}=7.44,95 \% \mathrm{CI} 5.81-9.51]$ ); and treatment role (referral from other hospitals [RR $=3.43,95 \%$ CI 2.62-4.49]).

The multivariable analysis found five diagnostic indicators that were significantly related to PUP: signs and symptoms including intense abdominal pain $(\mathrm{RR}=1.53,95 \% \mathrm{CI}$ 1.14-2.06), tenderness ( $\mathrm{RR}=1.94,95 \% \mathrm{CI} 1.17-3.21)$, and guarding ( $R R=1.52,95 \%$ CI 1.05-2.20); radiological finding of plain abdominal X-ray with free air $(\mathrm{RR}=2.80,95 \%$ CI 2.08-3.77); and referral from other hospitals ( $R R=1.37$, 95\% CI 1.03-1.82) (Table 2).

\section{Discussion}

Five diagnostic indicators, including three signs and symptoms of PUP (intense abdominal pain, tenderness, and guarding) were significantly different from peptic ulcer patients with no perforation. In the literature, ${ }^{2}$ it is suggested that gastrointestinal perforation often leads to catastrophic consequences. Erosion of the gastrointestinal wall by the ulcer leads to spillage of stomach or intestinal content into the abdominal cavity. Perforation at the anterior surface of the stomach leads to the first sign which is often sudden intense abdominal pain. Posterior wall perforation leads to tenderness and guarding, which often radiates pain to the back.

A plain abdominal X-ray, which showed free air, was used in the diagnosis of PUP in the hospital setting during the study period. A previous study used fast ultrasound or computerized tomography scan to confirm diagnosis and early treatment of PUP as plain abdominal X-ray does not always prove perforation, particularly in the early stages. ${ }^{14,15}$ Several case series have shown that in $30 \%-50 \%$ of patients, the X-ray may be negative for free air, particularly in the elderly. ${ }^{15}$ Unfortunately, ultrasound and computed tomography scans are limited in a developing country such as Thailand. Therefore, most cases in this study could not be confirmed by using this equipment. 
Table 2 Univariable and multivariable analysis risk ratio and $95 \%$ confidence interval of diagnostic indicators for peptic ulcer perforation

\begin{tabular}{|c|c|c|c|c|c|c|}
\hline Diagnostic indicators & Crude RR & $95 \% \mathrm{Cl}$ & $P$ value & Multivariable RR & $95 \% \mathrm{Cl}$ & $P$ value \\
\hline \multicolumn{7}{|l|}{ Gender } \\
\hline Female & 1.00 & Reference & & & Reference & \\
\hline Male & 1.55 & $(1.42-1.69)$ & $<0.001$ & 1.09 & $(0.94-1.27)$ & 0.263 \\
\hline \multicolumn{7}{|l|}{ Age (years) } \\
\hline$<60$ & 1.00 & Reference & & & Reference & \\
\hline$\geq 60$ & 2.29 & $(1.96-2.68)$ & $<0.001$ & 1.19 & $(0.90-1.58)$ & 0.22 \\
\hline \multicolumn{7}{|l|}{ Coexisting illnesses } \\
\hline \multicolumn{7}{|l|}{ Diabetes mellitus } \\
\hline No & 1.00 & Reference & & & Reference & \\
\hline Yes & 1.29 & $(1.07-1.55)$ & 0.006 & 0.97 & $(0.80-1.18)$ & 0.782 \\
\hline \multicolumn{7}{|l|}{ Hypertension } \\
\hline No & 1.00 & Reference & & & Reference & \\
\hline Yes & 0.66 & $(0.55-0.79)$ & $<0.001$ & 0.93 & $(0.76-1.15)$ & 0.525 \\
\hline \multicolumn{7}{|l|}{ COPD } \\
\hline No & 1.00 & Reference & & & Reference & \\
\hline Yes & 1.19 & $(0.93-1.53)$ & 0.175 & 0.96 & $(0.72-1.27)$ & 0.771 \\
\hline \multicolumn{7}{|l|}{ Asthma } \\
\hline No & 1.00 & Reference & & & Reference & \\
\hline Yes & 0.87 & $(0.28-2.7 I)$ & 0.811 & 1.08 & $(0.32-3.61)$ & 0.902 \\
\hline \multicolumn{7}{|l|}{ Liver cirrhosis } \\
\hline No & 1.00 & Reference & & & Reference & \\
\hline Yes & 1.75 & $(1.38-2.23)$ & $<0.001$ & 1.05 & $(0.82-1.34)$ & 0.719 \\
\hline \multicolumn{7}{|l|}{ Heart disease } \\
\hline No & 1.00 & Reference & & & Reference & \\
\hline Yes & 1.27 & $(1.04-1.54)$ & 0.018 & 1.05 & $(0.85-1.30)$ & 0.672 \\
\hline \multicolumn{7}{|l|}{ Renal disease } \\
\hline No & 1.00 & Reference & & & Reference & \\
\hline Yes & 0.90 & $(0.70-1.15)$ & 0.391 & 0.89 & $(0.69-1.17)$ & 0.408 \\
\hline \multicolumn{7}{|l|}{ Arthritis } \\
\hline No & 1.00 & Reference & & & Reference & \\
\hline Yes & 1.19 & $(0.93-\mid .5 I)$ & 0.161 & 1.25 & $(0.97-1.61)$ & 0.090 \\
\hline \multicolumn{7}{|l|}{ Personal habits } \\
\hline \multicolumn{7}{|l|}{ Smoking } \\
\hline No & 1.00 & Reference & & & Reference & \\
\hline Yes & 1.55 & $(1.33-1.8 I)$ & $<0.001$ & 1.07 & $(0.87-\mid .3 I)$ & 0.509 \\
\hline \multicolumn{7}{|l|}{ Alcohol consumption } \\
\hline No & 1.00 & Reference & & & Reference & \\
\hline Yes & 1.30 & $(I .|3-| .5 \mid)$ & $<0.001$ & 1.05 & $(0.86-1.29)$ & 0.605 \\
\hline \multicolumn{7}{|l|}{ NSAID usage } \\
\hline No & 1.00 & Reference & & & Reference & \\
\hline Yes & 1.22 & $(1.04-1.40)$ & 0.017 & 1.09 & $(0.92-1.29)$ & 0.333 \\
\hline \multicolumn{7}{|c|}{ History of peptic ulcer } \\
\hline No & 1.00 & Reference & & & Reference & \\
\hline Yes & 1.89 & $(1.64-2.19)$ & $<0.001$ & 1.13 & $(0.97-1.32)$ & 0.128 \\
\hline \multicolumn{7}{|l|}{ Signs and symptoms } \\
\hline \multicolumn{7}{|l|}{ Hematemesis } \\
\hline No & 1.00 & Reference & & & Reference & \\
\hline Yes & 0.74 & $(0.63-0.87)$ & $<0.001$ & 0.97 & $(0.8 I-I .16)$ & 0.716 \\
\hline Intense abdominal pa & & & & & & \\
\hline No & 1.00 & Reference & & & Reference & \\
\hline Yes & 5.25 & $(4.0 \mathrm{I}-6.88)$ & $<0.001$ & 1.53 & $(1.14-2.06)$ & 0.005 \\
\hline Tenderness & & & & & & \\
\hline No & 1.00 & Reference & & & Reference & \\
\hline Yes & 8.87 & $(6.00-13.12)$ & $<0.001$ & 1.94 & $(1.17-3.21)$ & 0.010 \\
\hline
\end{tabular}


Table 2 (Contiuned)

\begin{tabular}{|c|c|c|c|c|c|c|}
\hline Diagnostic indicators & Crude RR & $95 \% \mathrm{Cl}$ & $P$ value & Multivariable RR & $95 \% \mathrm{Cl}$ & $P$ value \\
\hline \multicolumn{7}{|l|}{ Guarding } \\
\hline No & 1.00 & Reference & & & Reference & \\
\hline Yes & 6.57 & $(5.00-8.62)$ & $<0.001$ & 1.52 & $(1.05-2.20)$ & 0.026 \\
\hline \multicolumn{7}{|l|}{ Melena } \\
\hline No & 1.00 & Reference & & & Reference & \\
\hline Yes & 0.50 & $(0.38-0.65)$ & $<0.00$ I & 0.86 & $(0.63-1.16)$ & 0.330 \\
\hline \multicolumn{7}{|c|}{ Systolic blood pressure $(\mathrm{mmHg})$} \\
\hline$\geq 100$ & 1.00 & Reference & & & Reference & \\
\hline$<100$ & 2.39 & $(\mathrm{I} .0 \mathrm{I}-2.77)$ & $<0.001$ & I.II & $(0.83-1.46)$ & 0.484 \\
\hline \multicolumn{7}{|c|}{ Pain onset time (hours) } \\
\hline$<24$ & 1.00 & Reference & & & Reference & \\
\hline$\geq 24$ & 2.45 & $(2.12-2.83)$ & $<0.001$ & 1.22 & $(0.99-1.50)$ & 0.058 \\
\hline \multicolumn{7}{|l|}{ Laboratory findings } \\
\hline \multicolumn{7}{|l|}{ Hemoglobin (g/dL) } \\
\hline$\geq 10$ & 1.00 & Reference & & 1.00 & Reference & \\
\hline$<10$ & 1.01 & $(0.98-1.04)$ & 0.488 & 1.01 & $(0.94-1.09)$ & 0.720 \\
\hline \multicolumn{7}{|l|}{ Hematocrit (\%) } \\
\hline$\geq 30$ & 1.00 & Reference & & 1.00 & Reference & \\
\hline$<30$ & 1.07 & $(0.92-1.23)$ & 0.381 & 1.00 & $(0.97-1.02)$ & 0.855 \\
\hline \multicolumn{7}{|l|}{ BUN/creatinin ratio } \\
\hline$<12$ & 1.00 & Reference & & & Reference & \\
\hline$\geq 12$ & 1.67 & $(1.39-2.01)$ & $<0.001$ & 1.08 & $(0.88-1.32)$ & 0.470 \\
\hline \multicolumn{7}{|l|}{ Radiological finding } \\
\hline \multicolumn{7}{|l|}{ X-ray with free air } \\
\hline No & 1.00 & Reference & & & Reference & \\
\hline Yes & 7.44 & $(5.8 I-9.5 I)$ & $<0.00$ I & 2.80 & $(2.08-3.77)$ & $<0.00$ I \\
\hline \multicolumn{7}{|l|}{ Treatment roles } \\
\hline \multicolumn{7}{|c|}{ Referral from other hospitals } \\
\hline No & 1.00 & Reference & & & Reference & \\
\hline Yes & 3.43 & $(2.62-4.49)$ & $<0.001$ & 1.37 & $(1.03-1.82)$ & 0.032 \\
\hline
\end{tabular}

Abbreviations: BUN, blood urea nitrogen; Cl, confidence interval; COPD, chronic obstructive pulmonary disease; NSAID, nonsteroidal antiinflammatory drug; RR, relative risk.

In the present study, patients who were referred from other hospitals were significantly associated with PUP. No previous studies have showed this data. Health services in Thailand are mainly provided by public hospitals run by the Ministry of Public Health, university hospitals, and the private sector. Public health services include small health centers covering 3000-5500 people, 10-60 bed community hospitals covering $20,000-40,000$ people, and $100-400$ bed provincial hospitals covering more than 200,000 people. ${ }^{16}$ A patient can visit any of these health services and then be referred to a larger hospital if the condition is serious. A number of studies concerning referral delays and secondary care delays in health care system have been previously reported. ${ }^{17,18}$ Data from the present study suggest that other hospital services play a very important role in determining the duration of system delay.

In summary, patient referral delays and lack of early detection of PUP in Thailand are important weaknesses with poor clinical outcomes. Severe PUP requires improved care management, avoidance of unnecessary medical treatment, and proper referral of patients. The referral system in Thailand may need revising. In addition, the findings of this study are useful for doctors and nurses in clinical practice in developing countries for early detection and treatment of PUP.

\section{Study strengths and weaknesses}

A strength of this study is its cohort design. The study was able to include all patients admitted to the surgical department with an accurate evaluation of patient characteristics and careful evaluation of patient records. Several diagnostic factors indicate this study to be valid: (1) large sample size of patients with PUP, (2) patient characteristics were based on real data from clinical practice, and (3) audit process was carefully planned and carried out with anonymous medical records; detailed medical records were reviewed by both surgical gastroenterologists and researchers.

A limitation of this study was the use of retrospective medical records that were sometimes incomplete. 
Unfortunately, it was not always possible to collect all risk factors, possibly because those filling out the documents had not accounted for a prospective study.

\section{Conclusion}

High-risk patients, ie, those who are referred from other hospitals with three signs and symptoms of PUP (intense abdominal pain, tenderness, and guarding) and present plain abdominal X-ray with free air, should be concerned. Reducing diagnostic delays in the referral system, with the intention of increasing the proportion of early detection of PUP, may improve patient outcomes in Thailand.

\section{Acknowledgments}

The authors thank the director of the Nakornping Hospital, the surgical department, nurses, hospital ward and other clerical staff, and others who provided information on their cases and for their contributions to the data collection.

\section{Disclosure}

The authors report no conflicts of interest in this work.

\section{References}

1. Higham J, Kang JY, Majeed A. Recent trends in admissions and mortality due to peptic ulcer in England: increasing frequency of haemorrhage among older subjects. Gut. 2002;50(4):460-464.

2. Lange A. Stomach and duodenum. In: Way LW, editor. Current Surgical Diagnosis and Treatment. 10th ed. Norwalk, CT: Appleton and Lange; 1994:437-459.

3. Noguiera C, Silva AS, Santos JN, et al. Perforated peptic ulcer: main factors of morbidity and mortality. World J Surg. 2003;27(7):782-787.

4. Akarca US. Gastrointestinal effects of selective and non-selective non-steroidal anti-inflammatory drugs. Curr Pharm Des. 2005;11(14): 1779-1793.
5. Kocer B, Surmeli S, Solak C, et al. Factors affecting mortality and morbidity in patients with peptic ulcer perforation. $J$ Gastroenterol Hepatol. 2007;22(4):565-570.

6. Aalykke C, Lauritsen K. Epidemiology of NSAID-related gastroduodenal mucosal injury. Best Pract Res Clin Gastroenterol. 2001; 15(5):705-722.

7. Arici C, Mesci A, Dincer D, Dinckan A, Colak T. Analysis of risk factors predicting (affecting) mortality and morbidity of peptic ulcer perforations. Int Surg. 2007;92(3):147-154.

8. Kum CK, Chong YS, Koo CC, Rauff A. Elderly patients with perforated peptic ulcers: factors affecting morbidity and mortality. J R Coll Surg Edinb. 1993;38(6):344-347.

9. Ministry of Public Health. Thailand Health Profile Report 2005-2007. 2007. Available from: http://www.moph.go.th/ops/thp/. Accessed August 31, 2009.

10. Canoy DS, Hart AR, Todd CJ. Epidemiology of duodenal ulcer perforation: a study on hospital admissions in Norfolk, United Kingdom. Dig Liver Dis. 2002;34(5):322-327.

11. IPD reported. Available from: http://www.nkp-hospital.go.th/IPD reported. htm. Accessed March 8, 2010.

12. Moller MH, Shah K, Bendix J, et al. Risk factors in patients surgically treated for peptic ulcer perforation. Scand J Gastroenterol. 2009; 44(2):145-152.

13. World Health Organization. International Statistical Classification of Diseases and Related Health Problems, 10th Revision (ICD-10). Geneva: World Health Organization; 1994.

14. Montoya Tabares MJ, Martin JL, Rios Zambudio A, Carrasco Prats M, Lopez Espejo J, Sanchez de la Villa G. Pneumomediastinum and subcutaneous emphysema-like manifestation of duodenal ulcer perforation. An Med Interna. 2007;24(1):48-49. Spanish.

15. Wallstabe L, Veitt R, Korner T. Diagnosis of perforated gastric ulcers by ultrasound. Z Gastroenterol. 2002;40(10):877-880.

16. Ministry of Public Health. Thailand Health Profile Report 2008-2010. 2010. Available from: http://www.moph.go.th/ops/thp/. Accessed August 22, 2011.

17. Neal RD, Allgar VL. Sociodemographic factors and delays in the diagnosis of six cancers: analysis of data from the "National Survey of NHS Patients: Cancer". Br J Cancer. 2005;92(11):1971-1975.

18. Rojpibulstit M, Kanjanakiritamrong J, Chongsuvivatwong V. Patient and health system delays in the diagnosis of tuberculosis in Southern Thailand after health care reform. Int J Tuberc Lung Dis. 2006; 10(4):422-428.
Clinical and Experimental Gastroenterology

\section{Publish your work in this journal}

Clinical and Experimental Gastroenterology is an international, peerreviewed, open access journal, publishing all aspects of gastroenterology in the clinic and laboratory, including: Pathology, pathophysiology of gastrointestinal disease; Investigation and treatment of gastointestinal disease; Pharmacology of drugs used in the alimentary tract;

\section{Dovepress}

Immunology/genetics/genomics related to gastrointestinal disease. This journal is indexed on CAS. The manuscript management system is completely online and includes a very quick and fair peer-review system. Visit http://www.dovepress.com/testimonials.php to read real quotes from published authors. 